\title{
Students' Environmental Awareness in Learning Environmental Pollution Using Instagram-mediated SAMR Model
}

\author{
Handina ${ }^{1}$, Diana Rochintaniawati ${ }^{2}$, Ikmanda Nugraha ${ }^{3}$ \\ \{handinadj@gmail.com ${ }^{1}$, dianarochintaniawati@upi.edu ${ }^{2}$, ikmandanugraha@upi.edu ${ }^{3}$ \} \\ International Program on Science Education, Faculty of Mathematics and Science Education, \\ Universitas Pendidikan Indonesia ${ }^{1,2,3}$
}

\begin{abstract}
Science education has an important role in assisting environmental awareness for students. However, limited class time and massive class size problems have restricted student participation and attempted thinking. Consequently, the class debate findings tend to end up being superficial, having little effect on the environenmental awareness of the students. This study seeks to explore the environmental awareness of students through the Instagram-mediated SAMR model in studying environmental pollution. Students engaged in this study were advised to follow an Instagram account by learning the subject, interacting with each other and the teacher, and submitting their vlog projects. An online questionnaire adapted from Hiramatsu consisting 5 factors of environmental awareness was used to collect information on the environmental awareness of the students. The finding on student environmental awareness demonstrates that students care about environmental problems. It is suggested that learning environmental pollution topic using Instagram-mediated SAMR model can facilitate student environmental awareness.
\end{abstract}

Keywords: Students Environmental Awareness, Environmental Pollution, SAMR Model, Instagram

\section{Introduction}

Environmental problems are the particular effect from human activities who have no social consciousness and only think about the particular profit without concern regarding the impact for the environment and their future life[1]. Among a plethora of environmental problems, extreme climate events are intensifying. Storms, droughts, and floods cause direct destruction, but also have pervasive repercussions on food security, infectious disease transmission, and economic stability that take their toll for many years[2]. Therefore, it is important for individuals to be environmentally aware.

It is believed that an individual's perspective on the environment is shaped by the experiences that they gain during school-age[3]. Therefore, environmental awareness needs to be promoted through environmental education. The executions can give attention to a domestic environmental problem to capture students' attention or their attention can be attracted on more abstract worldwide environmental problems[4]. This could also lead into integrating it with students' critical thinking skill in problem solving. Critical thinking is an 
important topic in modern education and learning[5], and it is also one of the several 21st century skills[6].

But in reality, due to the dense science curriculum in Indonesia, the problems of restricted class time and huge class size have limited students' participation and efforts of thoughts in class. Thus in class discussion outcomes tend to end up being superficial, having little influence on students' environmental awarenss and critical thinking. As a consequence, teachers are facing problems in designing revolutionary pedagogical approaches with the goal to set youthful thoughts thinking and to encourage critical thinking[5].

Researchers have been investigating the use of social media networks in teaching and learning. Social media is also very popular among the students due to its easy access from smartphones. Smartphones are accessible to fully $95 \%$ teens and according to $45 \%$ of them, they are online almost all the time[7]. This is a big opportunity to use online platforms, especially social media, in designing a revolutionary pedagogical approach for environmental education. Furthermore, another important factor will be the motivation of the students to the application of an online environment and the capability to display their own masterpieces [8]. By the suitable infrastructure and appropriate tools, social media networks can be used as learning tools, which will open the knowledge horizon of students in various issues[9].

There are many studies that investigated the use of different social media platforms from Facebook[9], YouTube[10] and factors that are involved in social media usage as learning tools[11]. However, there are very few studies - almost non-existent; that attempt to use one of the most popular social media networks, which is Instagram, especially in Indonesia. Since its launch in 2012, it has gained enormous popularity[12]. It is adverse that there are very little studies that use Instagram as a learning tool seeing the fact that Instagram reaches the younger generation and appeals more than other social networking services to diverse societies[13]. As a consequence, using Instagram as a learning tool might be difficult for teachers, adding to the complex nature of new digital technologies.

The complex nature of new digital technologies makes the already difficult task of teaching with technology more complicated[14]. Fortunately, researchers have developed standards, frameworks, models, and theories to guide educators and researchers in their efforts to integrate technology into teaching and learning that can be used to inform research and practice[15]. Puentedura's [16] Substitution, Augmentation, Modification, and Redefinition (SAMR) model is a recent approach to selecting, using, and evaluating technology. The SAMR model is intended to be a tool by which teachers' use of classroom technology can be described and categorized[16]. The model encourages teachers to move from lower to higher levels of technology-based teaching, leading to higher (i.e., enhanced) levels of teaching and learning, according to Puentedura[15]. The focus topic of this research is environmental pollution. This topic is suitable in this study because since students will make their own digital scrapbook by a presentation, their results (products) could be uploaded on the internet as a source of others peers for learning related to the topic and also may increase internet users' awareness towards environment. In learning environmental pollution, students will get the theoretical content that has to be understood and remembered. They will also get some theory with multiple teaching media for mastering the theory. However, students' are also expected to thoroughly explain certain phenomena regarding the topic. The clarification itself needs an interpretationthat could be achieved by a presentation. 


\section{Method}

The aim of this study is to capture and investigate the learning process, also students' critical thinking skill in learning environmental pollution using Instagram-mediated SAMR model. Based on the purpose of this research, this research is a descriptive study. Descriptive studies describe a given state of affairs as fully and carefully as possible[17]. Such studies look at individuals, groups, institutions, methods and materials in order to describe, compare, contrast, classify, analyse and interpret the entities and the events that constitute their various fields of inquiry[18]. It does not answer questions about how / when / why the features happened, but addresses the question of "what" (what are the features of the population or situation being studied?)[19]. The description is used for frequencies, averages and other calculations of statistics.

The design of this research is non-experimental with natural descriptive design as purposed to provide a description of educational phenomena. There is no independent variable manipulation. Researchers conducting non-experimental studies merely measure variables as they happen naturally, rather than manipulating an independent variable. Experimental study is suitable if the investigator has a particular study query or hypothesis on the causal connection between two variables - and the autonomous variable can be manipulated, viable and ethical. Therefore, it stands to reason that if these circumstances are not met, nonexperimental study is appropriate - even necessary[20]. The group members are not allocated randomly and the experimenter does not manipulate an independent variable, so no conclusions can be drawn about causal relationships between variables in the study[21]. Current situation of the research variables are elaborated descriptively and classified based on its type, characteristics or condition, then draw into conlcusion. Primarily descriptive in nature are the findings drawn from nonexperimental studies. Any efforts to draw conclusions about non-experimental research-based causal relationships are made after hoc[21].

This research was done in a private junior high school in West Bandung sub-district. The school has 3 classes for each grade and the number of the student for each class cannot be more than 30. For teaching and learning activity, the teachers and students use Indonesian as the language of instruction. 2013 curriculum is implemented in this school using modified curriculum which means the teacher may arrange the topics adjusting with the school's needs.

The population of this research is 7 th grade students in the second semester who are familiar with social media especially Instagram. Thus, the sampling technique that will be used is cluster random sampling. Cluster random sampling is selecting subject groups or clusters, not individuals. Cluster random sampling is similar to simple random sampling, other than that groups are randomly selected rather than individuals (i.e. The unit of sampling is a group rather than an individual). This sampling technique is considered suitable for this research because it is more efficient with larger cluster numbers[17].

During the second semester in the academic year of 2018-2019, an Instagram account of the school's science course and an Instagram direct message group has been created, in which 83 students of 7 th grade had the opportunity to communicate in various ways with the teacher who were using the science course Instagram and acted as the admin as well as their fellow students for the science course.

At the end of the course, the students who participated in the group were asked to upload a vlog regarding environmental pollution around them in which their critical thinking skills were measured. The total of 76 students completed the vlog project which consists of $91,6 \%$ of the sample. 


\section{Results and Discussion}

The data of students' environmental awareness was collected after the learning activity of environmental pollution topic using SAMR model through Instagram. The data was collected using a questionnaire adapted from Hiramatsu, Kurisu and Hanaki (2016). This questionnaire consists of 23 prompts that are derived from 5 factors of environmental awareness; personal responsibility, interest in attitude, awareness in daily life, judgment of others, and environmental information. The prompts are arranged randomly. This questionnaire uses 4-point Likert type items since no attempts were done by the researcher to combine the responses from the items into a composite scale[22].

The questionnaire was delivered to the students in the form of online questionnaire. The link to the questionnaire was sent to the students through the Instagram direct message group and personal direct message to make sure that all students saw the message.

\subsection{Students Response to Personal Responsibilty Prompts}

The first environmental awareness factor analyzed in this research is personal responsibility. This factor represents the psychological factor demonstrating self-awareness of accountability[23]. There are 9 prompts representing this factor in the questionnaire; "I do not care about environmental issues even if they were to destroy the earth in the future", "For me, there are more important things than environmental issues", "An individual inaction will not significantly influence the environment", "Individual action is important to solve environmental problems", "I do not think my behavior is responsible for global warming", "Individual action will not improve the environment", "Companies and industries should take more efforts than individuals to improve the environment", "In reality, I do not particularly care about the environment", "My concern for environmental issues is not particularly high".

Prompts representing the personality responsibility factor consist of both negative and positive prompts. There are 8 negative prompts and 1 positive prompt. The negative prompts are all prompts that represent this factor except the prompt that says, "Individual action is important to solve environmental problems".

The responses to the prompts in the form of Likert type items were recorded and the percentage of the answers to "strongly agree", "agree", "disagree", and "strongly disagree" is presented in Figure 1.

$91 \%$ of the students strongly disagree to the statement which states that they do not care about environmental issues even if they were to destroy the earth in the future. The redefinition stage of SAMR model had allowed the teacher to create a more novel and meaningful task in the form of vlog so the students could grow concerned seeing real examples of environmental pollution around them and actually analyze it as well as present it to the public. The statement regarding the importance of environmental problems to the student collected a prominent $30 \%$ answers that agree that there are more important things than environmental issues. The amount of disagreement to this statement shows that some students think that there are more important issues than environmental issues. In the augmentation level of SAMR model, the use of printed books as a learning tool was augmented by the use of Instagram account and it allowed the students to explore about other issues in the "explore" tab.

The next prompt which states that individual inaction will not significantly influence the environment got $47 \%$ students strongly disagree and $45 \%$ disagree to it. The students do realize that their individual actions can affect the environment. This is in accordance to the 
next prompts which show that $63 \%$ students strongly agree and $32 \%$ students agree that individual action is important in solving environmental problems. $68 \%$ students strongly disagree and $21 \%$ students disagree that individual action will not improve the environment. $50 \%$ strongly disagree and 36\% disagree that they do not care about the environment in reality. $29 \%$ strongly disagree and $53 \%$ disagree that their concerns for environmental issues are not high. The students agree that their actions impact the environment. It is represented in their environmental pollution vlogs where they explained about the efforts they consider important to be done to solve environmental problems around them.

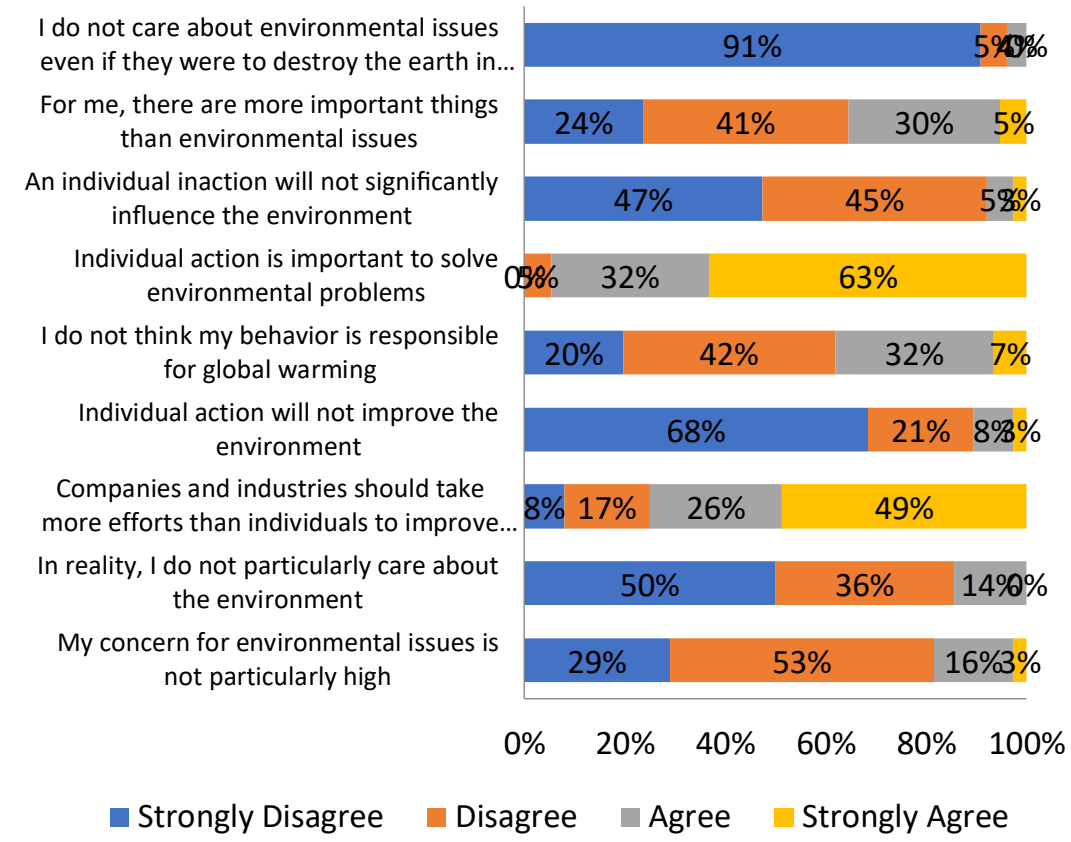

Fig. 1. Percentage of students' responses to each prompts representing the personal responsibility factor

For the item that says "I do not think my behavior is responsible for global warming", $20 \%$ students strongly disagre, $42 \%$ disagree, $32 \%$ agree, and $7 \%$ strongly agree. Their awareness towards global warming issue is relatively lower based on their answers to this prompt compared to their answers to other prompts regarding environmental pollution. In the substitution level of SAMR model where teacher substituted the use of printed books by the use of Instagram post to learn about the environmental pollution, the researcher did not emphasize about global warming. This is the same case with the next prompt that says "Companies and industries should take more efforts than individuals to improve the environment" since the researcher also did not emphasize about environmental pollution caused by industrial wastes.

The findings about this factor shows that the students understand that their role in the environment is important, therefore they need to have a high level of responsibility. This contradicts the previous finding which stated that people's misunderstanding of their role as a 
causative factor in environmental degradation causes them to resist altering their conduct, particularly when changing conduct is expensive or inconvenient[24].

\subsection{Students Response to Interest in Attitude Prompts}

Interest in attitude is the second environmental awareness factor analyzed in this research. This factor concerns the psychological factor of great concern in environmental issues and includes two positive prompts; "Environmental issues are important problems to be solved" and "PEBs should be adopted even if they are bothersome".

The responses to the prompts in the form of Likert type items were recorded and the percentage of the answers to "strongly agree", "agree", "disagree", and "strongly disagree" is presented in Figure 2.

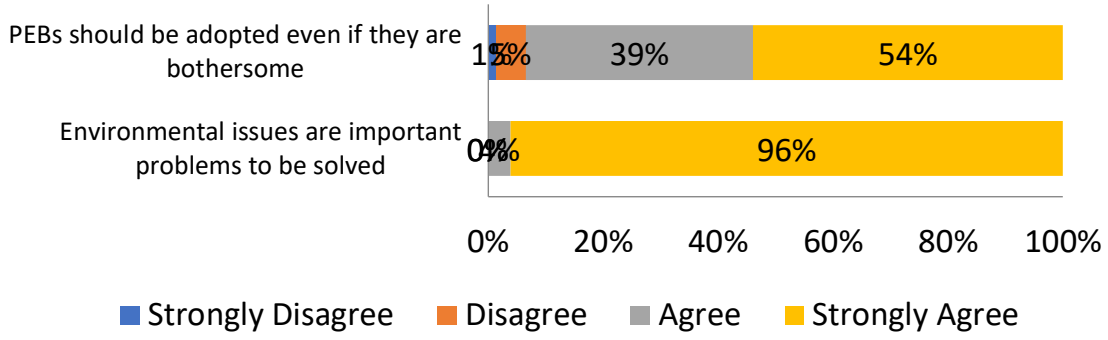

Fig. 2. Percentage of students' responses to each prompts representing the interest in attitude factor

The first prompt regarding their opinion about the adoption of pro environmental behavior got $54 \%$ students strongly agree and $39 \%$ students agree that PEBs should be adopted even if they are bothersome. The next prompt concerning the importance of environmental issues got $96 \%$ students strongly agree and the remaining $4 \%$ agree that environmental issues are important problems to be solved. This finding proves that students who are referred as millennials are frequently regarded as driving the sustainable movement with their lifestyle and behavioral modifications, from free-range meat to vegan skin care products. They are more likely to say that they would pay extra for environmentally friendly or sustainable products than any other generation[25].

The importance of environmental issues was discussed in the classroom with the guidance of the teacher while they were learning about some examples of environmental issues that are shown in the Instagram account. This level of technology integration is categorized as a augmentation because technology was exchanged and the tool's function shifts favorably[15].

\subsection{Students Response to Awareness in Daily Life Prompts}

The third environmental awareness factor analyzed in this research is awareness in daily life. This factor represents a psychological factor with low consciousness of the environment in everyday life[15]. There are 4 negative prompts representing this factor in the questionnaire; "I do not have enough time to actively change the environment", "When purchasing (e.g., energy, resources, waste), I do not particularly care about the environment", 
"Even if they are good for the environment, I avoid PEBs because I do not want to be inconvenienced", and "I display PEBs to save money".

The responses to the prompts in the form of Likert type items were recorded and the percentage of the answers to "strongly agree", "agree", "disagree", and "strongly disagree" is presented in Figure 3.

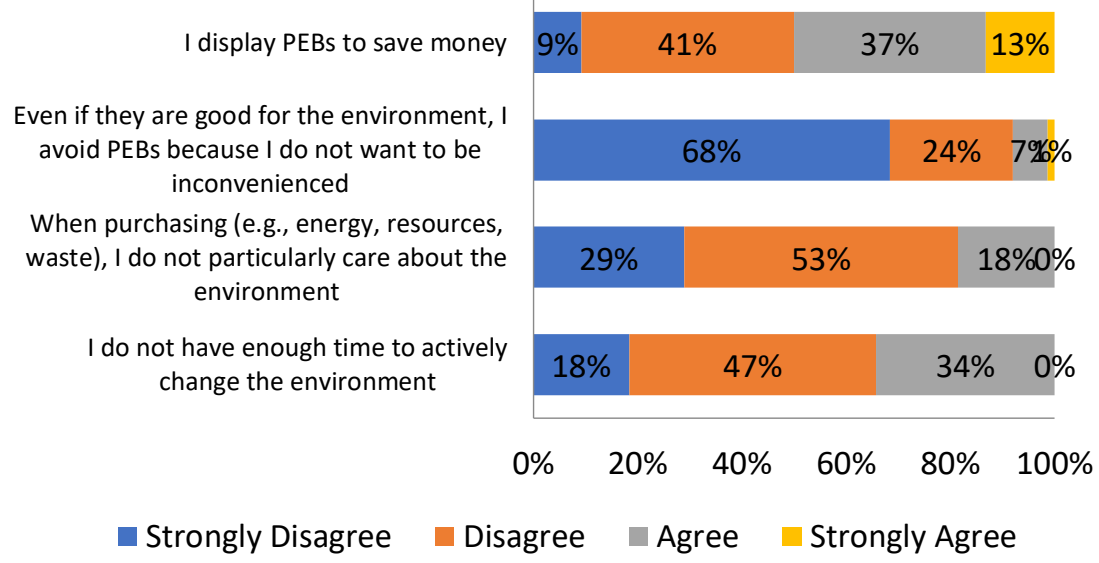

Fig. 3. Percentage of students' responses to each prompts representing the awareness in daily life factor

The statement which states that they display PEBs to save money got $9 \%$ of the students strongly disagree to it and $41 \%$ disagree. However, there are $37 \%$ of the students who agree that they display PEBs to save money. Meanwhile, $68 \%$ of the students strongly disagree and $24 \%$ disagree that they avoid doing PEBs because they do not want too be inconvenienced. In terms of purchasing something, 29\% strongly disagree and $53 \%$ disagree that they do not care about the environment. The prompt which states that they do not have enough time to actively change the environment got $18 \%$ strongly disagree and $47 \%$ disagree to it. This contradicts the previous finding using the same questionnaire which stated that in daily life, learners had far less accountability and consciousness than others, even though they expressed interest in environmental issues[23]. However, 34\% of the students somehow agree to the statement. Those who strongly disagree and agree to the statements representing this factor care about the environment when they buy or take different actions in their everyday lives[15].

\subsection{Students Response to Judgment of Others Prompts}

Judgment of others is the fourth environmental awareness factor analyzed in this research. This factor is concerning the psychological factor indicating knowledge of the decisions of others or their views[15]. There are 4 negative prompts representing this factor in the questionnaire; "My Pro-Environment Behaviors (PEBs) are based on custom rather than environmental consciousness", "I will not display PEBs when I do not have the attention of others or society", "I display PEBs depending on whether others are paying attention to my behaviors", and "I became fed up with being told to display PEBs". 
The responses to the prompts in the form of Likert type items were recorded and the percentage of the answers to "strongly agree", "agree", "disagree", and "strongly disagree" is presented in Figure 4.

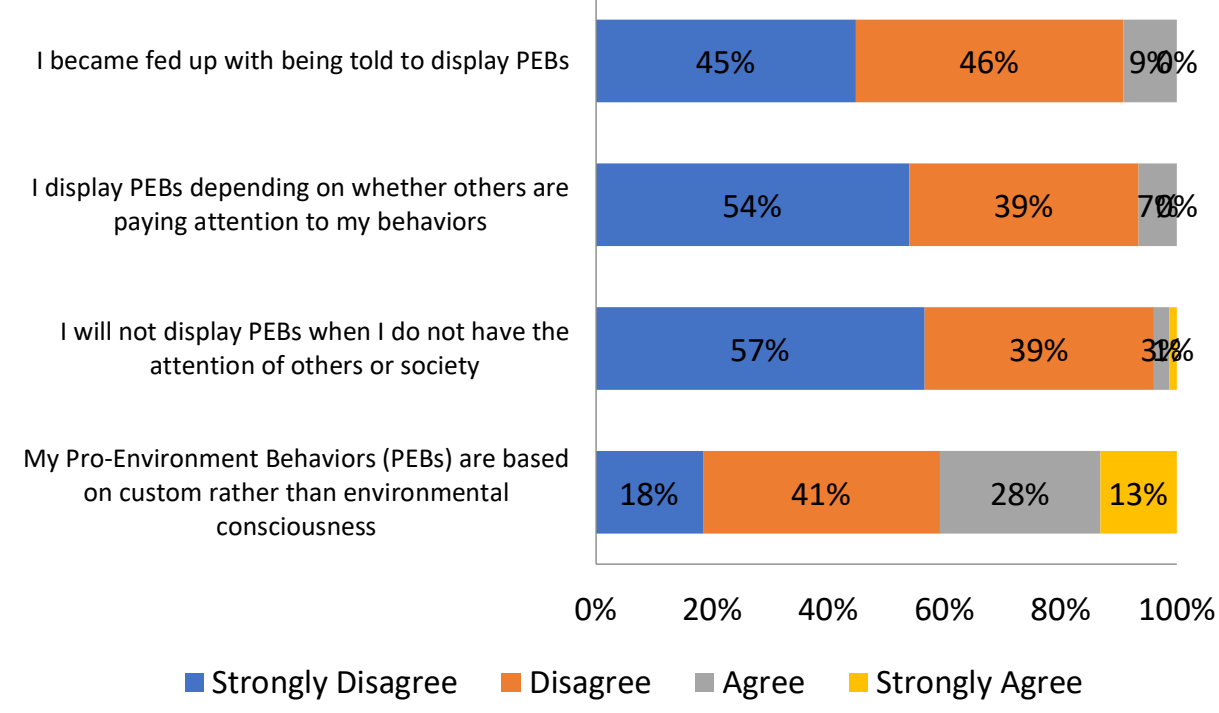

Fig. 4. Percentage of students' responses to each prompts representing the judgment of others factor

$45 \%$ of the students strongly disagree and $46 \%$ of them disagree that being told to display PEBs makes them fed up. The prompt that states that they display PEBs on whether others are paying attention to their behaviors got $54 \%$ of the students strongly disagree and $39 \%$ disagree to it. $57 \%$ of the students strongly disagree and $39 \%$ of them disagree that they will not display PEBs when they do not have the attention of others or society. Those 3 prompts got the majority of the students strongly disagree and disagree to them. This finding also contradicts the previous finding using the same questionnaire which stated that for the students, they care about others' perception and feel a lack of environmental information[23].

The last prompt representing this factor which states that their PEBs are based on custom rather than environmental consciousness got $18 \%$ of the students strongly disagree, $41 \%$ of them disagree, $28 \%$ agree and $13 \%$ strongly agree. Those who strongly agree and agree to those prompts perform PEBs depending on whether they feel other people or society as a whole are observing them, while those who strongly disagree and disagree to those prompts perform PEBs even when others are not paying attention to them. Vast majority of the students strongly disagree and disagree that they perform PEBs only when others are paying attention to them. This in in accordance with the personal responsibility factor result.

\subsection{Students Response to Environmental Information Prompts}

The fifth environmental factor observed in this research is environmental information. This factor represents the information shortage psychological sensing factor, including 4 negative prompts; "I do not know how much media information on the environment is reliable (TV, newspaper, internet, etc.)", "I cannot understand a person who is 
enthusiastic about environmental activities", "There is not enough useful information on adopting PEBs", "Honestly, I do not know what behaviors are good or bad for the environment".

The responses to the prompts in the form of Likert type items were recorded and the percentage of the answers to "strongly agree", "agree", "disagree", and "strongly disagree" is presented in Figure 5.

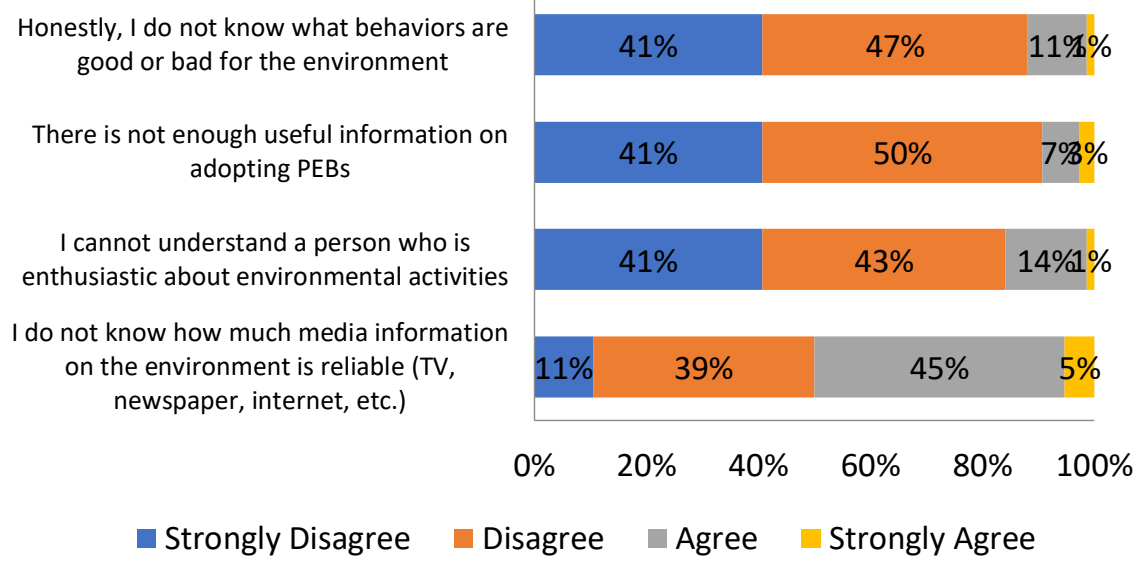

Fig. 5. Percentage of students' responses to each prompts representing the environmental information factor

The prompt which states that they do not know what behaviors are good or bad for the environment got $41 \%$ of the students strongly disagree and $47 \%$ of them disagree to it. $41 \%$ of the students strongly disagree and $50 \%$ of them disagree that there is not enough information on adopting PEBs. From the result of those two prompts we can imply that the students know what behaviors are good or bad for the environment and there is enough useful information on adopting PEBs. This contradicts the previous findings using the same questionnaire which stated that students feel a lack of environmental information[23].f They got the information about it through Instagram learning in the augmentation stage of SAMR model in which they learned about the behaviors posted in the Instagram account guided by the teacher instead of learning about it from the books. $41 \%$ of the students strongly disagree and $43 \%$ of them disagree that they cannot understand a person who is enthusiastic about environmental activities. This is in accordance with the results from previous prompts about information on adopting PEBs.

Regarding the reliability of the information, $39 \%$ of the students disagree that they do not know the reliability of the information they get from the media while a significant $45 \%$ of them agree that they do not know the reliability of the information they get from the media. It therefore appears that providing data that links individual behaviors to environmental harm is an important component of activating concrete environmental standards[24]. Government-led information campaigns, shaming individuals to feel guilty about their behaviour, using celebrities to promote a specific stance, and guiding or banning certain behaviour, or using taxes or subsidies to deter or encourage them, all can alter standards and associated behaviour[26]. This is one of the challenges in integrating technology with teaching and learning activity. All of the learning material in this research was delivered online through 
Instagram. It was new to the students so they did not know if the information was reliable since it was not accessed from their usual textbooks.

\section{Conclusion}

There are 5 factors of environmental awareness included in this research; personal responsibility, interest in attitude, awareness in daily life, judgment of others, and environmental information. The most prominent results showed that $91 \%$ students strongly disagree that they do not care about environmental issues and $96 \%$ students strongly agree that environmental issues are important problems to be solved. Most of the responds to the prompts in this this research contradict the previous findings.

\section{References}

[1] Hassan, A., et al.: The level of environmental awareness among students to fulfill the aspiration of national philosophy of education. American Journal of Scientific Research Vol. 5, pp. 50-58 (2009)

[2] Galvani, A. P., et al.: Human-environment interactions in population and ecosystem health. Proceedings of the National Academy of Sciences. Vol. 113, No. 51, pp. 14502-14506 (2016)

[3] Altin, A., et al.: Environmental awareness level of secondary school students: A case study in Balıkesir (Türkiye). Procedia-Social and Behavioral Sciences. Vol. 141, pp. 1208-1214 (2014)

[4] Simsekli, Y.: An implementation to raise environmental awareness of elementary education students. Procedia-Social and Behavioral Sciences, Vol. 191, pp. 222-226 (2015)

[5] Cheong, C. M. and Cheung, W. S.: Online discussion and critical thinking skills: A case study in a Singapore secondary school. Australasian Journal of Educational Technology. Vol. 24, No. 5, pp. 556-573 (2008)

[6] Lai, E. R. and Viering, M.: Assessing 21st Century Skills: Integrating Research Findings. The National Council on Measurement in Education. Vancouver, B.C., Pearson. Vol. 67 (2012)

[7] Anderson, M. and Jiang, J.: Teens, social media \& technology 2018. Pew Research Center 31 (2018)

[8] Duţă, N. and Martínez-Rivera, O.: Between theory and practice: the importance of ICT in Higher Education as a tool for collaborative learning. Procedia-Social and Behavioral Sciences. Vol. 180, pp. 1466-1473 (2015)

[9] Kolokytha, E., et al.: Social Media Networks as a Learning Tool. Procedia Economics and Finance. Vol. 19, pp. 287-295 (2015)

[10] Moghavvemi, S., et al.: Social media as a complementary learning tool for teaching and learning: The case of youtube. The International Journal of Management Education. Vol. 16, No. 1, pp. 37-42 (2018)

[11] Ali, M., et al.: Strengthening the academic usage of social media: An exploratory study. Journal of King Saud University-Computer and Information Sciences. Vol. 29, No. 4, pp. 553-561 (2016)

[12] Lee, E., et al.: Pictures speak louder than words: Motivations for using Instagram. Cyberpsychology, Behavior, and Social Networking. Vol. 18, No. 9, pp. 552-556 (2015)

[13] Abbott, W., et al.: An Instagram is worth a thousand words: An industry panel and audience Q\&A. Library Hi Tech News. Vol. 30, No. 7, pp. 1-6 (2013)

[14] Mishra, P., et al.: Looking back to the future of educational technology. TechTrends. Vol. 53, No. 5, pp. 49 (2009)

[15] Hamilton, E. R., et al.: The substitution augmentation modification redefinition (SAMR) model: A critical review and suggestions for its use. TechTrends. Vol. 60, No. 5, pp. 433-441 (2016)

[16] Puentedura, R.: Transformation, technology, and education. Retrieved February 18(2013), pp. 504-520 (2006) 
[17] Fraenkel, J. R., et al.: How to design and evaluate research in education, New York: McGrawHill Humanities/Social Sciences/Languages (2011).

[18] Cohen, L., et al.: Research methods in education, routledge (2002).

[19] Shields, P. M. and Rangarajan, N.: A playbook for research methods: Integrating conceptual frameworks and project management, New Forums Press (2013).

[20] Price, P. C., et al.: Research methods in psychology, BCCampus (2015)

[21] Salkind, N. J.: Encyclopedia of research design. Sage (2010)

[22] Boone, H. N. and Boone, D. A.: Analyzing likert data. Journal of extension. Vol. 50, No. 2, pp. $1-5(2012)$

[23] Hiramatsu, A., et al.: Environmental consciousness in daily activities measured by negative prompts. Sustainability. Vol. 8, No. 1, pp. 24 (2016).

[24] Vandenbergh, M. P.: The social meaning of environmental command and control. Va. Envtl. LJ 20 pp. 191 (2001)

[25] Young, K.: The Rise of Green Consumerism: What do Brands Need to Know? (2018)

[26] Carlson, A. E.: Recycling norms. Calif. L. Rev. Vol. 89, pp. 1231 (2001). 